\title{
Evaluasi Kesesuaian Lahan untuk Tanaman Padi Gogo, Jagung, Kedelai dan Kacang Tanah pada Lahan Kering di Kecamatan Jantho, Kabupaten Aceh Besar
}

\author{
Evaluation of the suitability of the land for rice plant Gogo, corn, soybeans and peanuts on \\ dry land in Jantho, Aceh Besar Regency
}

\author{
Hendra Saputra ${ }^{1}$, Syakur $^{1}$, Manfarizah $^{1 *}$ \\ ${ }^{1}$ Program Studi Agroteknologi, Fakultas Pertanian, Universitas Syiah Kuala
}

\begin{abstract}
ABSTRAK
Luas lahan dataran di Indonesia lebih kurang 200 juta hektar dan luas lahan kering 150 juta hektar. Hampir seluruh daratan Indonesia setelah dikurangi lahan basah (sawah dan rawa) lahan kering yang berpotensi sebagai areal pertanian diperkirakan mencapai 104 juta hektar. Penelitian ini bertujuan untuk menganalisis kesesuaian lahan untuk tanaman padi gogo, jagung, kedelai dan kacang tanah pada lahan kering. Penelitian ini dilaksanakan di Kecamatan Jantho, Kabupaten Aceh Besar dengan menggunakan metode survai deskriptif yang didasarkan pada satuan peta lahan. Satuan peta lahan diperoleh dari hasil tumpang tindih (overlay) peta jenis tanah, peta kelerengan dan peta penggunaan lahan. Hasil (overlay) tersebut yang menjadi referensi untuk menentukan kelas kesesuaian lahan. Hasil evaluasi kesesuaian lahan tanaman padi yaitu (S2-nr,eh,lp) cukup sesuai dengan faktor pembatas utama kejenuhan basa (KB) dan C-organik rendah, bahaya erosi dan kelerengan 8-15\% dan (S3-nr,eh) sesuai marginal dengan faktor pembatas utama C-organik sangat rendah dan kelerengan $15-25 \%$. Kesesuaian lahan tanaman jagung yaitu (S2-nr,eh) cukup sesuai dengan faktor pembatas utama KB rendah dan bahaya erosi dan (S3-nr,eh) sesuai marginal dengan faktor pembatas utama KB sangat rendah dan kelerengan 15-25\%. Kesesuaian lahan tanaman kedelai yaitu (S2-nr,eh,lp) cukup sesuai dengan faktor pembatas utama kapasitas tukar kation (KTK), KB, C-organik yang rendah dan kelerengan 8-15\% dan (S3-eh) sesuai marginal dengan faktor pembatas utama kelerengan 15-25\%. Kesesuaian lahan tanaman kacang tanah yaitu (S2-nr,eh,lp) cukup sesuai dengan faktor pembatas utama KTK, KB, pH, C-organik yang rendah dan batuan di permukaan 5-15\% dan (S3-nr,eh) sesuai marginal dengan faktor pembatas utama KB sangat rendah dan kelerengan 15-25\%.
\end{abstract}

Kata kunci : lahan kering, evaluasi lahan, kimia tanah

\begin{abstract}
Land area of the plains in Indonesia approximately 200 million hectares of dry land area and 150 million acres. Almost all of Indonesia's land after reduced wetlands (swamps and rice paddies) as potentially dry land agricultural area is estimated at 104 million hectares. This research aims to analyze the suitability of land for rice plant gogo, corn, soybeans and peanuts on dry land. This research was carried out in Jantho, Aceh Besar District by using descriptive survey method that is based on a unit of land maps. Land map units retrieved from a result of overlap (overlay) map kelerengan map, soil type and land use maps. The results (overlay) which became a reference to determine the suitability of the land class. The results of the evaluation of the suitability of the land for rice plant (S2-nr, er, lp) is quite in accordance with the main limiting factor saturation of the base (KB) and the C-organic low, the danger of erosion and kelerengan 8-15\% and (S3-nr, er) in accordance with marginal to the main limiting factor C-organic very low and kelerengan $15-25 \%$. The suitability of the land for corn plants (S2-nr, er) is quite in accordance with the main limiting factor KB is low and the danger of erosion and (S3-nr, er) in accordance with marginal to the main limiting factor KB is very low and kelerengan $15-25 \%$. The suitability of the land for soybean crop i.e. (S2-nr, er, lp) is quite in accordance with the main limiting factor cation exchange capacity (CEC), KB, the low C-organic and kelerengan 8-15\% and (S3-eh) in accordance with the main limiting factor of marginal kelerengan $15-25 \%$. The suitability of the land plants peanuts (S2-nr, er, lp) is quite in accordance with the main limiting factor $\mathrm{CEC}, \mathrm{KB}, \mathrm{pH}$, organic $\mathrm{C}$-low and rocks on the surface of 5$15 \%$ and $(\mathrm{S} 3-\mathrm{nr}$, er) in accordance with marginal to the main limiting factor $\mathrm{KB}$ is very low and kelerengan 15 $25 \%$.
\end{abstract}

Key words: dry land, land evaluation, soil chemistry 


\section{PENDAHULUAN}

Indonesia merupakan salah satu negara besar yang mempunyai luas lahan daratan kurang lebih 200 juta hektar atau kira-kira 1,5\% luas daratan yang tersebar di empat pulau besar yaitu di Sumatera, Kalimantan, Sulawesi dan Irian Jaya sekitar 162 juta hektar (85\%) sedangkan sisanya 38 juta hektar (15\%) ada di Jawa, dan Maluku (Suripin, 2004).

Luas lahan kering di Indonesia sekitar 150 juta hektar, sedangkan lahan basah sekitar 39 juta hektar yang meliputi rawa lebak, pasang surut dan gambut. Jika lahan yang mempunyai kemiringan 0-15\% dianggap potensial untuk dikembangkan, maka di luar pulau Jawa ada 34,6 juta hektar, dikelola untuk pertanian sekitar 5,8 juta ha sehingga masih ada cadangan sekitar 28,8 juta ha. Hampir seluruh daratan Indonesia setelah dikurangi lahan basah (lahan sawah dan rawa) merupakan lahan kering yang berpotensi sebagai areal pertanian diperkirakan mencapai 104 juta hektar dan luas ini terus mengalami penurunan seiring adanya ekspansi pertanian pada lahan-lahan kering marginal (Haridjaja, 1990).

Pemanfaatan lahan kering untuk pengembangan pertanian khususnya tanaman pangan yaitu padi gogo, jagung, kedelai dan kacang tanah sering kali diabaikan oleh para pengambil kebijakan, yang lebih tertarik pada peningkatan produksi pangan pada lahan sawah walaupun isu lama tetapi masih merupakan permasalahan terkait pengembangan tanaman pangan di lahan kering dengan keterbatasan air, kesuburan tanah yang rendah, rentan erosi, dan topografi bergelombang sampai berbukit (Haridjaja, 1990).

Lahan kering yang sesuai secara biofisik namun lahan tersebut telah digunakan untuk penggunaan lain, misalnya untuk perkebunan, pemukiman, sarana transportani, atau statusnya berada dalam kawasan yang tidak boleh dialihfungsikan menjadi lahan pertanian, misalnya suaka margasatwa atau hutan lindung (Suwarto et al., 2012).

Permasalahan lahan kering di Jantho Kabupaten Aceh Besar adalah masih kurang dimanfaatkan oleh masyarakat atau lahan sering ditelantarkan karena adanya keterbatasan air yang terdapat pada lahan kering, hanya bergantung pada tingkat curah hujan sebagai sumber air sehingga perlu optimalisasi yang baik dalam pemanfaatan lahan kering.

\section{METODE PENELITIAN}

\section{Tempat dan Waktu Penelitian}

Penelitian ini dilakukan di Kecamatan Jantho Kabupaten Aceh Besar. Analisis tanah dilakukan di Laboratorium Tanah dan Tanaman Fakultas Pertanian dan pembuatan peta dilakukan di Laboratorium Penginderaan Jauh dan Kartografi Fakultas Pertanian Universitas Syiah Kuala. Penelitian ini dilaksanakan bulan Juni sampai November 2016

\section{Bahan dan Alat Penelitian}

Alat yang digunakan dalam penelitian ini adalah sebagai berikut: GPS (global positioning system), bor tanah, cangkul, pisau, kantong plastik, buku munsell soil color chart, alat tulismenulis dan software ArcGIS 10.2.

Bahan yang digunakan dalam penelitian ini adalah sebagai berikut: peta administrasi, peta jenis tanah, peta lereng, peta penggunaan lahan dan peta rencana kerja pengambilan sampel tanah masing-masing dengan skala 1:50.000 yang didapatkan dari Bappeda Provinsi Aceh. Adapun bahan kimia yang digunakan antara lain: larutan aquades, $\mathrm{H}_{2} \mathrm{O}_{2} 10 \%, 0,5 \mathrm{~N}$ $\mathrm{HCl}$, dan bahan kimia lainnya untuk analisis sampel tanah di laboratorium. 
Penelitian ini menggunakan metode survai deskriptif yang didasarkan pada hasil observasi di lapangan dengan menggunakan sistem taktis berdasarkan pada satuan peta lahan (SPL). Pengambilan sampel dilakukan di titik pengamatan dengan cara menggunakan bor tanah, sebagaimana tertera dalam lampiran peta rencana kerja. Data dasar untuk evaluasi kesesuaian lahan dan pengumpulan data sekunder seperti data iklim di kumpulkan dari BMKG (Balai Meteorologi Klimatologi dan Geofisika) Indrapuri Kabupaten Aceh Besar dengan jumlah yang diambil selama sepuluh tahun. Sistem pengambilan sampel digunakan dengan sistem acak yang telah ditentukan di areal SPL yaitu setiap SPL diambil dua sampel tanah, kemudian sampel tanah tersebut dianalisis di laboratorium.

\section{Pelaksanaan Penelitian}

Tahapan dalam penelitian ini adalah: (1) persiapan, (2) kegiatan lapangan, (3) pengumpalan data, (4) analisis dan tabulasi data.

\section{Tahap Awal/ Persiapan}

Tahap persiapan dilakukan studi kepustakaan yang menyangkut dengan daerah penelitian baik publikasi resmi maupun melalui buku. Persiapan peta yaitu tumpang tindih (overlay) peta jenis tanah, peta lereng dan peta penggunaan lahan dengan skala 1:50.000 dan persiapan Satuan Peta Lahan (SPL) sementara dan rencana kerja lapangan.

\section{Kegiatan Lapangan}

Tahap awal survai tanah adalah dilakukan dengan menggunakan acuan pengamatan lapanagan. Setiap Satuan Peta Lahan dilakukan pengamatan sifat-sifat tanah, pengamatan pada jenis tana, lereng, penggunaan lahan dan kondisi biofisik lainnya yang terdapat pada lokasi penelitian. Pengamatan sifat fisik tanah dilakukan pada setiap hasil pengeboran tanah dengan kedalaman 0-30 cm dan sifat morfologi lahan yang diamati dapat dilihat di bawah ini.

Tabel 1. Data morfologi yang diamati di lapangan

\begin{tabular}{lll}
\hline No & Karakteristik Yang Diamati & Metode Pengamatan Lapangan \\
\hline 1 & Lereng & Pengamatan dengan Abney Level \\
2 & Batuan Permukaan & Pengamatan persentase batuan pada luasan tertentu \\
3 & Kedalaman Efektif & Pengamatan dengan pengeboran tanah \\
4 & Tekstur Tanah & Pemijitan tanah (ibu jari dan telunjuk) \\
5 & pH Lapangan & pH tancap \\
6 & Drainase & Pengamatan penampang profil tanah \\
7 & Bahaya Erosi & Melihat kerapatan vegetasi penutup tanah dan melihat \\
& & persentase lereng \\
\hline
\end{tabular}

Sumber: CSR/FAO (1983)

\section{Analisis Laboratorium}

Contoh tanah yang sudah diambil dari lapangan dilakukan analisis di laboratorium dengan jenis dan metode penelitian dapat dilihat pada Tabel 2.

Tabel 2. Jenis dan metode analisis tanah

\begin{tabular}{lll}
\hline No & Jenis Analisis & Metode Analisis \\
\hline 1 & pH tanah (dalam $\left.\mathrm{H}_{2} \mathrm{O}\right)$ & $\mathrm{pH}$ meter (electrometrik) \\
2 & C-organik & Walkley and Black \\
3 & KTK (kapasitas tukar kation) & Ekstraksi $1 \mathrm{~N} \mathrm{NH}_{4} \mathrm{COOCH}_{3} \mathrm{pH}_{7}$ \\
4 & KB (kejenuhan basa) & Kation basa/KTK x $100 \%$ \\
\hline
\end{tabular}

Sumber: CSR/FAO (1983) 


\section{Pengumpulan Data}

Pengumpulan data mencakup data sekunder dan primer. Data sekunder didapat dari hasil penelitian serta literatur yang terkait dengan penelitian ini dan didapat dari instansi terkait. Data primer didapatkan dari data iklim, curah hujan dan karakteristik lahan.

Data iklim berguna untuk mengetahui kondisi iklim dalam ketersediaan air bagi pertumbuhan tanaman. Iklim yang diperhatikan adalah jumlah hari hujan dan jumlah curah hujan rata-rata dalam sepuluh tahun terakhir (2006-2015).

Karakteristik lahan yang diamati adalah kimia tanah dan sifat fisik tanah. Sifat kimia tanah dianalisis di Laboratorium sedangkan sifat fisik tanah diamati dengan cara pengeboran tanah pada setiap titik pengeboran.

\section{Analisis dan Tabulasi}

Hasil analisis data di lapangan dan di laboratorium digunakan sebagai dasar dalam mengklasifasikan kelas kesesuaian lahan dalam pembuatan peta lahan. Kriteria klasifikasi kesesuaian lahan yang digunakan adalah menurut FAO 1976.

Dari hasil ini akan diketahui kelas kesesuaian lahan untuk tanaman padi, jagung, kedelai dan kacang tanah di Kecamatan Jantho Kabupaten Aceh Besar. Analisis dilakukan untuk menilai kelayakan fisik suatu daerah guna untuk tanaman yang ingin dikembangkan. Pada tahap analisis kesesuaian lahan disusun penggunaan lahan yang disesuaikan dengan tujuan penelitian. Data yang didapat dari lapangan dan di laboratorium selanjutnya dilakukan pengolahan dan dilanjutkan pembuatan peta kesesuaian lahan.

Hasil overlay peta jenis tanah, peta lereng dan peta penggunaan lahan menghasilkan satuan peta lahan (SPL) yang menjadi referensi untuk menentukan kelas kesesuaian lahan.

\section{HASIL DAN PEMBAHASAN}

\section{Satuan Peta Lahan}

Hasil penelitian Jantho Kabupaten Aceh Besar memiliki delapan satuan peta lahan (SPL) yang diperoleh dari hasil overlay peta lereng, peta jenis tanah dan peta penggunaan lahan. Berdasarkan observasi di lapangan didapatkan bentuk wilayah dari datar $(<8 \%)$ hingga yang sangat curam (> 25\%). Setiap SPL mempunyai jenis tanah yang berbeda-beda yakni Inceptisol, Ultisol dan Entisol. Uraian secara rinci dapat dilihat pada Tabel 3 berikut:

Tabel 3. Karakteristik Satuan Peta Lahan di Kecamatan Jantho, Kabupaten Aceh Besar

\begin{tabular}{|c|c|c|c|c|c|}
\hline \multirow{2}{*}{ SPL } & \multirow{2}{*}{ Jenis Tanah } & \multirow{2}{*}{ Lereng } & \multirow{2}{*}{ Penggunaan Lahan } & \multicolumn{2}{|c|}{ Luas } \\
\hline & & & & $\mathrm{Ha}$ & $\%$ \\
\hline 1 & Entisol & $<8 \%$ & Semak Belukar & 652,19 & 12,61 \\
\hline 2 & Entisol & $15-25 \%$ & Pertanian Lahan Kering & 461,91 & 8,93 \\
\hline 3 & Entisol & $<8 \%$ & Pertanian Lahan Kering & $1.309,99$ & 25,32 \\
\hline 4 & Entisol & $8-15 \%$ & Pertanian Lahan Kering & 105,43 & 2,04 \\
\hline 5 & Inseptisol & $<8 \%$ & Pertanian Lahan Kering & 867,78 & 16,77 \\
\hline 6 & Ultisol & $8-15 \%$ & Pertanian Lahan Kering Sekunder & 755,99 & 14,61 \\
\hline 7 & Ultisol & $15-25 \%$ & Semak Belukar & 348,25 & 6,73 \\
\hline 8 & Ultisol & $<8 \%$ & Pertanian Lahan Kering Sekunder & 671,93 & 12,99 \\
\hline & Total & & & $5.173,47$ & 100 \\
\hline
\end{tabular}

Sumber: Hasil overlay peta (2016).

\section{Satuan Peta Lahan 1}

Pada satuan lahan ini mempunyai bentuk wilayah landai/ berombak $(<8 \%)$ dengan batuan pemukaan (0-5\%), satuan peta lahan untuk lapisan top soil ini mempunyai $\mathrm{pH}_{2} \mathrm{O}$ $(5,89)$ agak asam, dengan C-organik $(0,72 \%)$ sangat rendah, dan KTK $\left(13,6\right.$ me $\left.100 \mathrm{~g}^{-1}\right)$ 
rendah, dan adapun KB $(28,24 \%)$ rendah, sedangkan untuk lapisan sub soil mempunyai $\mathrm{pH}$ $\mathrm{H}_{2} \mathrm{O}(5,95)$ agak asam, dengan C-organik $(0,55 \%)$ sangat rendah, dan KTK $\left(16,8\right.$ me $\left.100 \mathrm{~g}^{-1}\right)$ rendah, dan adapun KB $(21,49 \%)$ rendah.

\section{Satuan Peta Lahan 2}

Pada satuan lahan ini mempunyai bentuk wilayah miring/berbukit (15-25\%) dengan batuan pemukaan (0-5\%), satuan peta lahan untuk lapisan top soil ini mempunyai $\mathrm{pH}_{2} \mathrm{O}$ $(5,85)$ agak asam, dengan C-organik $(1,06 \%)$ rendah, dan KTK $\left(14,4\right.$ me $\left.100 \mathrm{~g}^{-1}\right)$ rendah, dan adapun $\mathrm{KB}(81,81 \%)$ sangat tinggi, sedangkan untuk lapisan sub soil mempunyai $\mathrm{pH}_{2} \mathrm{H}_{2} \mathrm{O}$ $(6,20)$ agak asam, dengan C-organik $(0,64 \%)$ sangat rendah, dan KTK $\left(15,2\right.$ me $\left.100 \mathrm{~g}^{-1}\right)$ rendah, dan adapun $\mathrm{KB}(82,28 \%)$ sangat tinggi.

\section{Satuan Peta Lahan 3}

Pada satuan lahan ini mempunyai bentuk wilayah landai/ berombak $(<8 \%)$ dengan batuan pemukaan (0-5\%), satuan peta lahan untuk lapisan top soil ini mempunyai $\mathrm{pH}_{2} \mathrm{O}$

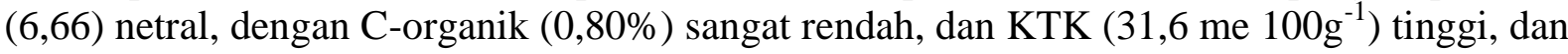
adapun KB $(30,82 \%)$ rendah, sedangkan untuk lapisan sub soil mempunyai $\mathrm{pH} \mathrm{H}_{2} \mathrm{O}(6,67)$ netral, dengan C-organik (0,70\%) sangat rendah, dan KTK (34,8 me $\left.100 \mathrm{~g}^{-1}\right)$ tinggi, dan adapun KB $(20,57 \%)$ rendah.

\section{Satuan Peta Lahan 4}

Pada satuan lahan ini mempunyai bentuk wilayah agak miring/bergelombang (8-15\%) dengan batuan pemukaan (0-5\%), satuan peta lahan untuk lapisan top soil ini mempunyai $\mathrm{pH}$ $\mathrm{H}_{2} \mathrm{O}(5,73)$ agak asam, dengan C-organik $(0,80 \%)$ sangat rendah, dan KTK $\left(23,2\right.$ me $\left.100 \mathrm{~g}^{-1}\right)$ sedang, dan adapun KB (26,72\%) rendah, sedangkan untuk lapisan sub soil mempunyai $\mathrm{pH}$ $\mathrm{H}_{2} \mathrm{O}(5,66)$ agak asam, dengan C-organik $(0,69 \%)$ sangat rendah, dan KTK $\left(22,0\right.$ me $\left.100 \mathrm{~g}^{-1}\right)$ sedang, dan adapun KB $(15,00 \%)$ sangat rendah.

\section{Satuan Peta Lahan 5}

Pada satuan lahan ini mempunyai bentuk wilayah landai/ berombak $(<8 \%)$ dengan batuan pemukaan yang sedang (5-15\%), satuan peta lahan untuk lapisan top soil ini mempunyai $\mathrm{pH} \mathrm{H}_{2} \mathrm{O}(6,10)$ agak asam, dengan C-organik $(1,12 \%)$ rendah, dan KTK $(24,0$ me $\left.100 \mathrm{~g}^{-1}\right)$ sedang, dan adapun $\mathrm{KB}(28,54 \%)$ rendah, sedangkan untuk lapisan sub soil mempunyai $\mathrm{pH} \mathrm{H}_{2} \mathrm{O}(6,85)$ netral, dengan C-organik $(0,36 \%)$ sangat rendah, dan KTK $(34,0$ me $\left.100 \mathrm{~g}^{-1}\right)$ tinggi, dan adapun KB $(12,82 \%)$ sangat rendah.

\section{Satuan Peta Lahan 6}

Pada satuan lahan ini mempunyai bentuk wilayah agak miring/bergelombang (8-15\%) dengan batuan pemukaan (0-5\%), satuan peta lahan untuk lapisan top soil ini mempunyai $\mathrm{pH}$ $\mathrm{H}_{2} \mathrm{O}(6,21)$ agak asam, dengan C-organik $(1,01 \%)$ rendah, dan KTK $\left(15,2\right.$ me $\left.100 \mathrm{~g}^{-1}\right)$ rendah, dan adapun $\mathrm{KB}(27,71 \%)$ rendah, sedangkan untuk lapisan sub soil mempunyai $\mathrm{pH} \mathrm{H}_{2} \mathrm{O}$ $(6,07)$ netral, dengan C-organik $(0,39 \%)$ sangat rendah, dan KTK $\left(26,0\right.$ me $\left.100 \mathrm{~g}^{-1}\right)$ tinggi, dan adapun KB $(15,19 \%)$ sangat rendah.

\section{Satuan Peta Lahan 7}

Pada satuan lahan ini mempunyai bentuk wilayah miring/berbukit (15-25\%) dengan batuan pemukaan (0-5\%), satuan peta lahan untuk lapisan top soil ini mempunyai $\mathrm{pH}_{2} \mathrm{O}$ $(5,94)$ agak asam, dengan C-organik $(0,72 \%)$ sangat rendah, dan KTK $\left(14,4\right.$ me $\left.100 \mathrm{~g}^{-1}\right)$ rendah, dan adapun $\mathrm{KB}(28,22 \%)$ rendah, sedangkan untuk lapisan sub soil mempunyai $\mathrm{pH}$ $\mathrm{H}_{2} \mathrm{O}(6,11)$ agak asam, dengan C-organik $(0,72 \%)$ sangat rendah, dan KTK $\left(14,8 \mathrm{me}^{\left.100 \mathrm{~g}^{-1}\right)}\right.$ rendah, dan adapun KB (30,78\%) sedang.

\section{Satuan Peta Lahan 8}

Pada satuan lahan ini mempunyai bentuk wilayah landai/berombak $(<8 \%)$ dengan batuan pemukaan (0-5\%), satuan peta lahan untuk lapisan top soil ini mempunyai $\mathrm{pH}_{2} \mathrm{O}$ $(5,71)$ agak asam, dengan C-organik $(1,82 \%)$ rendah, dan KTK $\left(25,6\right.$ me $\left.100 \mathrm{~g}^{-1}\right)$ tinggi, dan 
adapun $\mathrm{KB}(25,80 \%)$ sedang, sedangkan untuk lapisan sub soil mempunyai $\mathrm{pH} \mathrm{H}_{2} \mathrm{O}(6,01)$ agak asam, dengan C-organik (0,38\%) sangat rendah, dan KTK (20,4 me $\left.100 \mathrm{~g}^{-1}\right)$ rendah, dan adapun KB $(27,10 \%)$ sedang.

\section{Sifat Fisik Tanah}

Tanah memiliki sifat fisik, biologi maupun kimia yang berbeda-beda dan juga pada lingkungan yang berbeda. Keadaan sifat fisik yang baik dapat memperbaiki lingkungan untuk perakaran tanaman dan secara tidak langsung memudahkan penyerapan hara sehingga relatif mengutungkan pertumbuhan tanaman (Arifin, 2010). Berdasarkan observasi di lapangan sifat fisik Kecamatan Jantho yang meliputi kelerengan, drainase, kedalaman efektif, bahaya erosi, warna tanah, batuan permukaan dan tekstur, dapat dilihat pada Tabel 4.

Tabel 4. Sifat Fisik Tanah di Kecamatan Jantho, Kabupaten Aceh Besar

\begin{tabular}{|c|c|c|c|c|c|c|c|}
\hline \multirow[b]{2}{*}{ SPL } & \multicolumn{7}{|c|}{ Karakteristik Lahan } \\
\hline & Lereng & Drainase & $\begin{array}{l}\text { Kedalaman } \\
\text { Efektif }\end{array}$ & $\begin{array}{c}\text { Bahaya } \\
\text { Erosi }\end{array}$ & $\begin{array}{l}\text { Warna } \\
\text { Tanah }\end{array}$ & $\begin{array}{c}\text { Batuan } \\
\text { Permukaan }\end{array}$ & Tekstur \\
\hline 1 & $<8 \%$ & Lambat & $60 \mathrm{~cm}$ & $\begin{array}{l}\text { Sangat } \\
\text { Rendah }\end{array}$ & $\begin{array}{c}7,5 \mathrm{YR} \\
4 / 3\end{array}$ & $0-5 \%$ & B \\
\hline 2 & $15-25 \%$ & Sedang & $60 \mathrm{~cm}$ & Rendah & $\begin{array}{c}7,5 \text { YR } \\
6 / 4\end{array}$ & $0-5 \%$ & A \\
\hline 3 & $<8 \%$ & Sedang & $60 \mathrm{~cm}$ & $\begin{array}{l}\text { Sangat } \\
\text { Rendah }\end{array}$ & $\begin{array}{c}5 \mathrm{YR} \\
3 / 3\end{array}$ & $0-5 \%$ & $\mathrm{C}$ \\
\hline 4 & $8-15 \%$ & Lambat & $60 \mathrm{~cm}$ & $\begin{array}{l}\text { Sangat } \\
\text { Rendah }\end{array}$ & $\begin{array}{c}7,5 \mathrm{YR} \\
4 / 3\end{array}$ & $0-5 \%$ & B \\
\hline 5 & $<8 \%$ & Sedang & $60 \mathrm{~cm}$ & $\begin{array}{l}\text { Sangat } \\
\text { Rendah }\end{array}$ & $\begin{array}{c}7,5 \mathrm{YR} \\
5 / 4\end{array}$ & $5-15 \%$ & A \\
\hline 6 & $8-15 \%$ & Sedang & $60 \mathrm{~cm}$ & $\begin{array}{l}\text { Sangat } \\
\text { Rendah }\end{array}$ & $\begin{array}{c}7,5 \mathrm{YR} \\
4 / 3\end{array}$ & $0-5 \%$ & B \\
\hline 7 & $15-25 \%$ & Lambat & $60 \mathrm{~cm}$ & Rendah & $\begin{array}{c}5 \mathrm{YR} \\
3 / 3\end{array}$ & $0-5 \%$ & $\mathrm{C}$ \\
\hline 8 & $<8 \%$ & Sedang & $60 \mathrm{~cm}$ & Rendah & $\begin{array}{c}7,5 \mathrm{YR} \\
5 / 4\end{array}$ & $0-5 \%$ & A \\
\hline
\end{tabular}

Sumber: Hasil Pengamatan di Lapangan (2016).

Keterangan
A : Liat
B : Lempung
C : Lempung Berpasir

\section{Sifat Kimia Tanah}

Permasalahan teknis yang terjadi pada lahan kering adalah produktivitas usaha tani masih rendah, salah satu penyebabnya adalah keadaan tanah yang kurang subur akibat dari erosi yang terjadi, lahan kering juga sangat peka terhadap kekeringan, rendahnya tingkat kesuburan tanah yang dicirikan oleh: (1) tingginya tingkat kemasaman tanah, (2) kekahatan hara P, K, Ca dan Mg, (3) rendahnya kapasitas tukar kation (KTK), (4) kejenuhan basa dan kandungan bahan organik, dan (5) tingginya kadar Al dan Mn dapat meracuni tanaman (Sujitno et al., 2011). Hasil analisis tanah yang diamati di laboratorium terhadap sifat kimia tanah yaitu: $\mathrm{pH} \mathrm{H}_{2} \mathrm{O}$, C-Organik, Kapasitas Tukar Kation (KTK) dan Kejenuhan Basa (KB) seperti pada Tabel 5 . 
Tabel 4. Sifat Kimia Tanah di Kecamatan Jantho, Kabupaten Aceh Besar

\begin{tabular}{cccccc}
\hline SPL & $\begin{array}{c}\text { Kedalaman } \\
\text { Tanah } \\
(\mathrm{cm})\end{array}$ & $\mathrm{pH} \mathrm{H}_{2} \mathrm{O}$ & $\begin{array}{c}\text { C-Organik } \\
(\%)\end{array}$ & $\begin{array}{c}\text { Kapasitas } \\
\text { Tukar Kation } \\
(\mathrm{me} / 100 \mathrm{~g})\end{array}$ & $\begin{array}{c}\text { Kejenuhan Basa } \\
(\%)\end{array}$ \\
\hline 1 & $0-30$ & 5,89 & 0,72 & 13,6 & 28,2 \\
& & 5,95 & 0,55 & 16,8 & 21,4 \\
2 & $0-30$ & 5,85 & 1,06 & 14,4 & 81,8 \\
& & 6,20 & 0,64 & 15,2 & 82,2 \\
3 & $0-30$ & 6,66 & 0,80 & 31,6 & 30,8 \\
& & 6,67 & 0,70 & 34,8 & 20,5 \\
4 & $0-30$ & 5,73 & 0,80 & 23,2 & 26,7 \\
& & 5,66 & 0,69 & 22,0 & 15,0 \\
5 & $0-30$ & 6,10 & 1,12 & 24,0 & 28,5 \\
& & 6,85 & 0,36 & 34,0 & 12,8 \\
6 & $0-30$ & 6,21 & 1,01 & 15,2 & 27,7 \\
& & 6,07 & 0,39 & 26,0 & 15,1 \\
7 & $0-30$ & 5,94 & 0,72 & 14,4 & 28,2 \\
& & 6,11 & 0,72 & 14,8 & 30,7 \\
8 & $0-30$ & 5,71 & 1,82 & 25,6 & 25,8 \\
& & 6,01 & 0,38 & 20,4 & 27,1 \\
\hline
\end{tabular}

Sumber: Hasil Analisis Laboratorium (2016)

Dari Tabel 8 menunjukkan kandungan unsur hara atau sifat kimia tanah di Kecamatan Jantho, Kabupaten Aceh Besar:

1. Kemasaman $\mathrm{pH}$

Nilai $\mathrm{pH}$ di Kecamatan Jantho dapat dikatakan cukup netral walaupun sebenarnya agak asam dengan nilai $\mathrm{pH}$ yang berkisar antara 5,66 sampai 7,07 dan rata-rata tanah mempunya nilai $\mathrm{pH} 5,0$ dan 6,0. Nilai $\mathrm{pH}$ berkisar dari 0-14 dengan $\mathrm{pH} 7$ disebut netral sedangkan $\mathrm{pH}$ kurang dari 7 disebut masam dan $\mathrm{pH}$ lebih dari 7 disebut alkalis atau basa. Nilai pH juga sangat berpengaruh dalam evaluasi kesesuaian lahan karena $\mathrm{pH}$ menjadi salah satu unsur hara yang dibutuhkan tanaman selain C-organik, kapasitas tukar kation dan kejenuhan basa.

2. Kadar C-organik

Kandungan bahan organik dalam tanah merupakan salah satu faktor yang berperan dalam menentukan keberhasilan suatu budidaya pertanian. Di lokasi penelitian menunjukan kadar c-organik yang sangat rendah dengan nilai berkisar antara 0,36\% sampai 1,12\%. Agar kandungan bahan organik dalam tanah tidak menurun seiring waktu akibat proses dekomposisi mineralisasi maka sewaktu pengolahan tanah penambahan bahan organik mutlak harus diberikan setiap tahun seperti memberikan pupuk kandang dan pupuk hijau. Sehingga tanah tersebut akan lebih layak lagi untuk budidaya tanaman dan dapat pula meningkatkan KTK karena C-organik berkaitan erat dengan KTK.

3. Kapasitas Tukar Kation (KTK)

Tanah-tanah dengan kandungan bahan organik atau kadar liat tinggi mempunyai KTK lebih tinggi daripada tanah-tanah dengan kandungan bahan organik rendah atau tanah-tanah berpasir (Hardjowigeno, 2003). Hasil analisis laboratorium nilai KTK yang didapatkan bahwa sedang yang berkisar antara 13,6 me/100g sampai 34,8 me/100g. Besar kecilnya KTK dipengaruhi oleh reaksi tanah, tekstur atau jumlah liat, jenis mineral liat, bahan organik, pengapuran serta pemupukan dan tergantung pada sifat dan ciri tanah itu sendiri.

4. Kejenuhan Basa (KB)

Kejenuhan basa menunjukkan perbandingan antara jumlah kation-kation basa dengan jumlah semua kation (kation basa dan kation asam) yang terdapat dalam kompleks jerapan 
tanah. Jumlah maksimum kation yang dapat dijerap tanah menunjukkan besarnya nilai kapasitas tukar kation tanah tersebut. Kation-kation basa umumnya merupakan unsur hara yang diperlukan tanaman. Disamping itu basa-basa umumnya mudah tercuci, sehingga tanah tersebut belum banyak mengalami pencucian dan merupakan tanah yang subur. Kejenuhan basa berhubungan erat dengan $\mathrm{pH}$ tanah, dimana tanah-tanah dengan $\mathrm{pH}$ rendah umumnya mempunyai kejenuhan basa rendah, sedang tanah-tanah dengan $\mathrm{pH}$ yang tinggi mempunyai kejenuhan basa yang tinggi pula (Soewandita, 2008).

\section{Kesimpulan}

\section{KESIMPULAN DAN SARAN}

Berdasarkan data dan pembahasan dapat diambil simpulan:

1. Kelas kesesuaian lahan tanaman padi gogo termasuk dalam kriteria cukup sesuai (S2) dengan luas 3.711,12 Ha dan kriteria sesuai marginal (S3) dengan luas 1.462,35 Ha.

2. Kelas kesesuaian lahan tanaman jagung termasuk dalam kriteria sesuai marginal (S3) dengan luas 3.191,55 Ha dan kriteria cukup sesuai (S2) dengan luas 1.981,92 Ha.

3. Kelas kesesuaian lahan tanaman kedelai termasuk dalam kriteria cukup sesuai (S2) dengan luas 4.363,31 Ha dan kriteria sesuai marginal (S3) dengan luas 1.981,92 Ha.

4. Kelas kesesuaian lahan tanaman kacang tanah termasuk dalam kriteria cukup sesuai (S2) dengan luas 3.711,12 Ha dan kriteria sesuai marginal (S3) dengan luas 1.462,35 Ha.

5. Setiap kelas kesesuaian lahan aktual dari empat jenis tanaman memiliki faktor pembatas masing-masing dan dapat dilakukan perbaikan atau perubahan dari kesesuaian aktual menjadi kesesuaian potensial dengan usaha perbaikan (input) berupa pemupukan baik itu organik atau anorganik, membuat terassering atau memotong lereng supaya tidak mudah terjadi erosi dan mengolah lahan seperti membersihkan lahan dan memindahkan batuan permukaan dari dalam lahan. Maka setelah dilakukan berbagai macam perbaikan, lahan tersebut layak di gunakan untuk tanaman padi gogo, jagung, kedelai dan kacang tanah.

\section{DAFTAR PUSTAKA}

Arifin, M. 2010. Kajian sifat fisik tanah dan berbagai penggunaan lahan dalam hubungannya dengan pendugaan erosi tanah. Jurnal Pertanian MAPETA, ISSN : 1411-2817. 12 (2). P. 111. Jawa Timur.

Haridjaja, O., K. Murtilaksono, Sudarmo dan L. M. Rachman. 1990. Hidrologi Pertanian. Jurusan Tanah Fakultas Pertanian Institut Pertanian Bogor. Bogor.

Soewandita, H. 2008. Studi Kesuburan Tanah dan Analisis Kesesuaian Lahan untuk Komoditas Tanaman Perkebunan di Kabupaten Bengkalis. Jurnal Sains dan Teknologi Indonesia. 10 (2). Hal 132. Bengkulu.

Suripin, 2004. Pengembangan Sistem Drainase yang Berkelanjutan. Andi Offset. Yogyakarta.

Suwarto, Suwarto dan S, Anantanyu, 2012. Model partisipasi petani lahan kering dalam konversi lahan. Jurnal Ekonomi Pembangunan. 13 (2). P. 221. Surakarta. 